\title{
Theoretical research to accomplish a system of ecological heating a greenhouse for vegetables
}

\author{
Eugen Marin ${ }^{1, *}$, Marinela Mateescu ${ }^{1}$, Dragos Manea ${ }^{1}$, Andrei Dumitrascu ${ }^{1}$, Carmen \\ Vasilachi ${ }^{1}$, Radu Popa $^{1}$, Vlad Popa $^{1}$ \\ ${ }^{1}$ National Institute of Research-Development for Machines and Installations designed to Agriculture \\ and Food Industry-INMA Bucharest 013813, Romania
}

\begin{abstract}
Considerating that the energy resources can be found in limited quantities and are not renewable, the most efficient and technically sustainable for heating the soil in early spring or late autumn in a greenhouse for vegetables is to use the solar energy. A heated greenhouse for vegetables is useful because the vegetation process can start more early or can continue later for can obtain several crops throughout the year. The paper presents theoretical researches accomplished for development an system of ecological heating in a greenhouse covered with a tough polyethylene wrap with triple layer. The heating system contains solar panels with heat-pipe vacuum tubes and an installation for heating the interior of the solarium using hot water hot air heaters, which adds more heat.
\end{abstract}

\section{Introduction}

In Romania, studies have been carried out to increase the energy independence of greenhouses with small dimensions, for example, the use of a TLUD gasification system, which uses the energy potential of agricultural residues [1]. For the use of agricultural residues in a process of energy recovery through gasification, it is necessary to grind to a size of $5 \mathrm{~cm}$ of the splinters, and the maximum humidity of the material should be a maximum $20 \%$ [2].

Due to the fact that the use of systems for the production of hot water is made with high costs, the most often used heating system is the one that uses flat solar collectors because it is simple and economical [3]. Lately, the researchers have emphasized the use of solar energy in the technical applications for heating greenhouses and solariums, due to the high storage performance and the efficiency of its conversion [4].

In areas of Western Europe, Central Europe, and Eastern Europe, around noon, under a perfectly clear sky and free of pollution, unit thermal energy received from the Sun can be a maximum $1000 \mathrm{~W} / \mathrm{m}^{2}$ (as the sum of the direct radiation and diffused), which is measured perpendicular to the direction of the sun's rays on the surface of the Earth [5].

* Corresponding author: marin 43eu@yahoo.com 
In Romania, the values of the thermal flux of the diffused solar radiation in the horizontal plane are directly influenced by the position of the Sun with respect to the surface normal and the South direction having approximate values from $25 \mathrm{Wh} / \mathrm{m}^{2}$ in the winter months to $62 \mathrm{Wh} / \mathrm{m}^{2}$ in the summer months [6].

There are multiple possibilities for developing the use of solar energy for heating greenhouses and solariums especially in the South-East and South-Muntenia Region, according to the schematic map of the global solar radiation in Romania from Fig. 1.

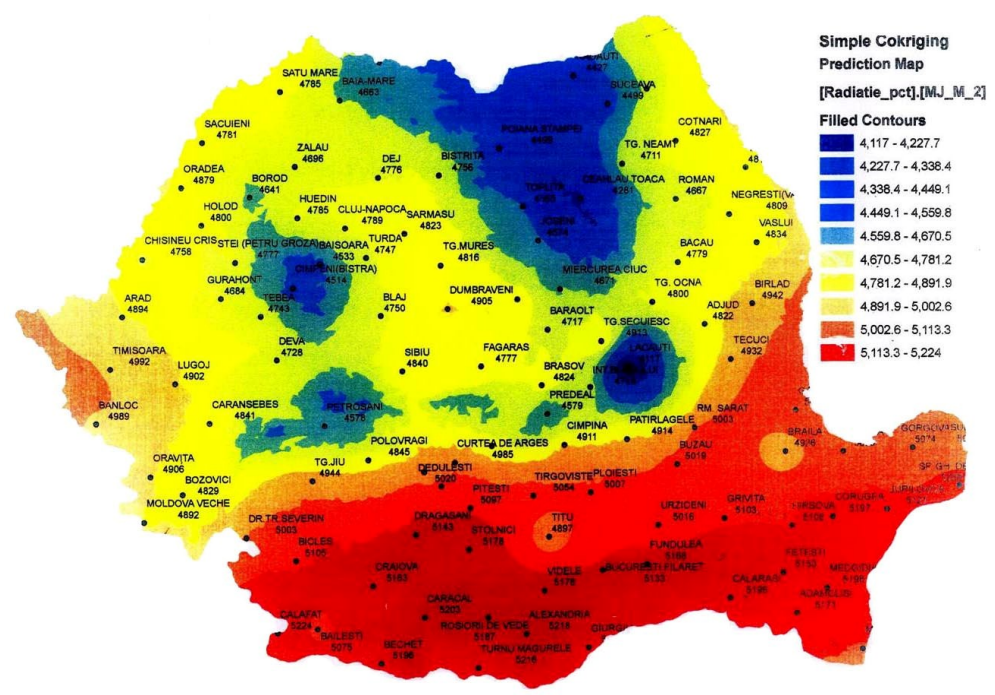

Fig. 1. Schematic map of global solar radiation in Romania [7].

The flat solar collectors (solar collector, solar thermal panel), which are designed to transform the incident solar radiation into usable heat, do not allow to following the Sun for increase the conversion efficiency, because of this the maximum efficiency (Fig. 2) is obtained only for an interval short time during a day [8].

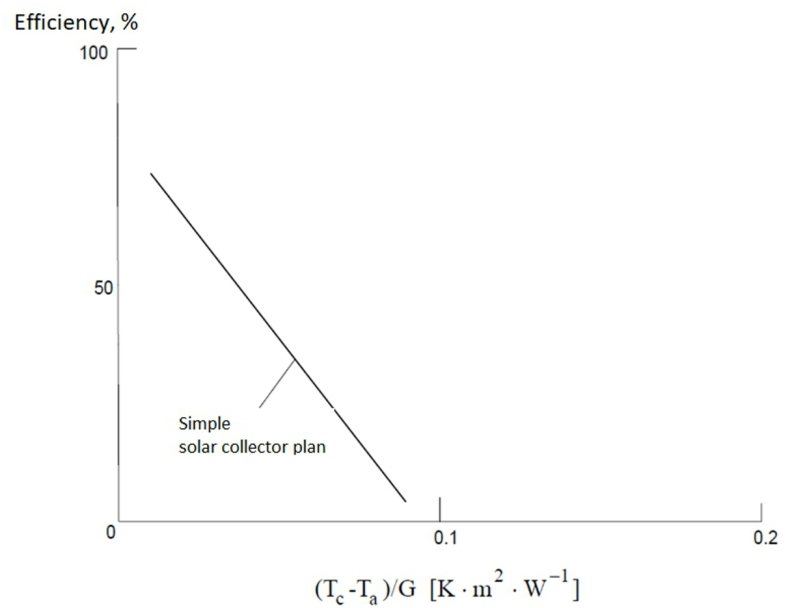

Fig. 2. Variation of the plane collector yield curvewhere, $\mathrm{G}$ is the incident radiation on the collector surface, in $\mathrm{W} / \mathrm{m}^{2}$, and $\mathrm{T}_{\mathrm{c}}$ and $\mathrm{T}_{\mathrm{a}}$ are the temperatures in the collector respectively the ambient temperature, in $\mathrm{K}$. 
There are concerns about increasing the efficiency of converting solar energy into thermal energy at solar collectors, which involves efficient capture of solar radiation.

Between a solar panel with vacuum head-pipe and a flat solar panel for domestic use, the annual yield can increase by 5 to 10 percent. [9].

Researching to account the requirements of efficient use of solar collectors that have a high percentage of solar radiation which reaches on that surface and transforms into thermal energy, INMA Bucharest has designed an experimental model of system of ecological heating needed of an agricultural farm that uses energy solar for the contribution of heat for the purpose of heating a vegetable solarium in order to grow crops during the cold time of the year (October-December and February-April).

The installation for producing heat supply uses two solar panels with 30 vacuum heatpipe from copper of $24 \mathrm{~mm}$ Sontec SPA 30 58/1800, which are the most efficient in terms of capturing solar energy because the borosilicate glass layer and the vacuum inside has the role of giving a 96\% efficiency (solar energy falling on the panel, compared to the energy captured by the panel). These panels can provide $70-80 \%$ of the heat input in the cold season [10].

\section{Methodology}

The purpose of this work was the correct sizing of the heat production installation in order to warm a vegetable greenhouse with the following characteristics [11]: width: $9 \mathrm{~m}$, length: $30 \mathrm{~m}$, height of the ridge: $4.05 \mathrm{~m}$, the height of the pillars: $2.35 \mathrm{~m}$, arch distance: 2.5 $\mathrm{m}$, metallic structure: from round pipe E260 premium steel, galvanized with $275 \mathrm{gZn} / \mathrm{m}^{2}$, coating: three-layered greenhouse film $200 \mu \mathrm{m}$ that has the following properties: resistance: UV (ultraviolet), EVA (elongation): 600\%, outer layer: anti-dust, transparency: $90 \%$, diffusion: $25 \%$, inner layer: anti-condensation, thickness: $0.20 \mathrm{~mm}$

In order to obtain the maximum yield of capturing the intensity of the direct and diffuse solar radiation, the installation of the heat supply has been dimensioned taking into account the following factors:

- the thermal energy produced by a solar collector during a day, has been observed to depend on the temperature of the thermal agent and that of the environment [12];

- the value of the intensity of solar radiation, which according to the specialized literature is influenced by: geographical region, altitude, temperature and humidity of the air, degree of air pollution, the average number of sunny hours during a day, positioning of the Sun according to the calendar month, but also by the inclination of the capture panels, the materials used in the construction, the working fluids etc;

- the volume of the greenhouse to be heated.

A special role in the design of the heat supply installation for the vegetable greenhouse had to adapt to the climatic conditions, so that during a sunny day it was considered that the entire surface area of the solar collector to be directly exposed to solar radiation for at least 4 hours during the months of October -December and February -April.

The temperature of the environment influences the thermal parameters, which is why it was taken into account the average temperature in the winter months November - March which is $2.34^{\circ} \mathrm{C}$, considering the historical weather data per hour for 30 years for Bucharest provided by the National Administration of Meteorological.

In Fig. 3 is the graph for the "daily average maximum" (continuous red line) that shows the maximum average temperature of the day for each month for Bucharest [13].

Another important role in the design of the plant for the production of heat in the vegetable greenhouse also had the influence of the shadow areas and the obstacles that were estimated by a calculation method for determining the solar radiation that will be available in a sunny day during a year. 


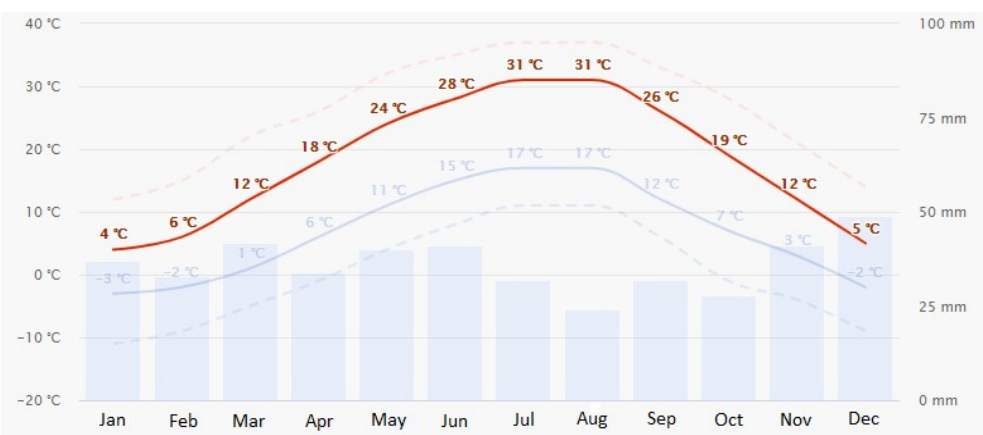

Fig. 3. Graphical representation of the average maximum temperature of one day for each month in Bucharest

According to the data provided by the National Administration of Meteorological, the ultraviolet global solar radiation, regardless of the time of year, shows an ascending daytime flow in the first part of the day, until afternoon, when the rule is reached, the maximum values. In the second part of the day, ultraviolet radiation shows a descent movement. To perform the analysis of the influence of the intensity of the solar radiation and implicitly of the heat flow received by the solar installation, the site https://www.meteoblue.com [15] offers sufficient information on the values of temperature, solar radiation, direct radiation and diffusion depending on by the geographical region of the location of the solar collectors. Based on the values offered by Meteoblue, charts were drawn regarding the values of temperature, solar radiation, direct and diffuse radiation. In Fig. 4 are represented graphically the values of temperature, solar radiation, direct and diffuse radiation realized during the period 24.03.2020-31.03.2020 from Bucharest.

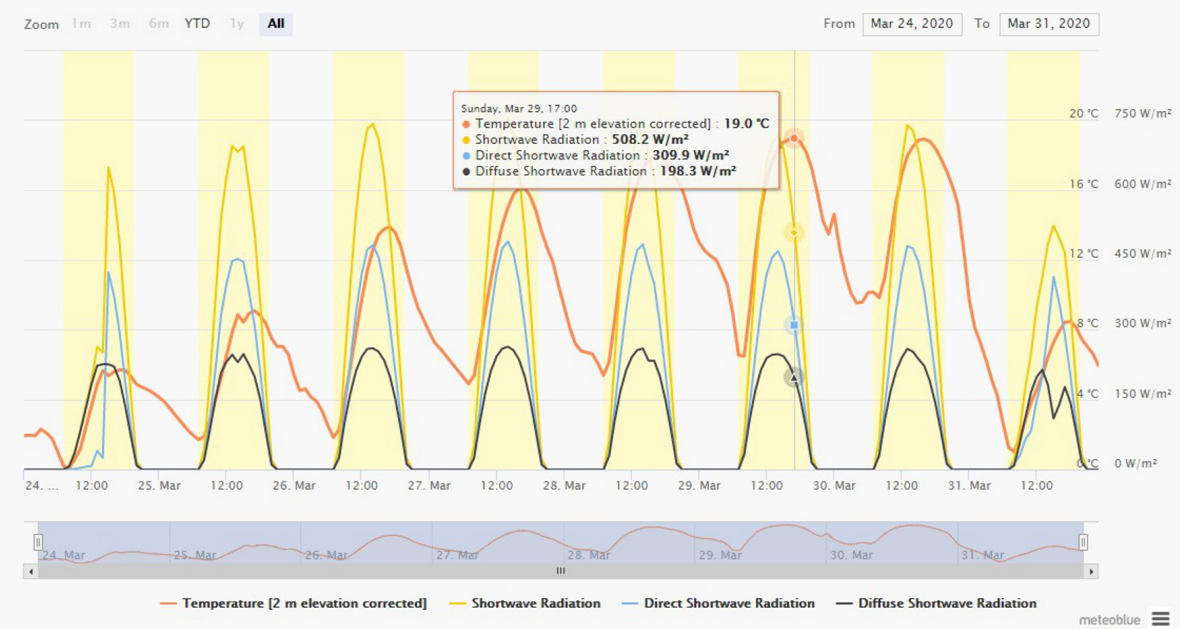

Fig. 4. Graphical representation values of the temperature, solar radiation, direct and diffuse radiation in period 24.03.2020 to 31.03.2020 from Bucharest

From the analysis of the graph presented in Fig. 4, it is observed that at 17:00 when the maximum temperature reached was $19^{\circ} \mathrm{C}$, the solar radiation had a value of 508.2 $\mathrm{W} / \mathrm{m}^{2}$, the direct radiation had a value of $309.9 \mathrm{~W} / \mathrm{m}^{2}$, and the radiation diffuse represented $39.02 \%$ of the solar radiation. Accessing the database of the Meteoblue site, we could make a graphical representation of the temperature and solar radiation achieved during the same period 24.03.2020-31.03.2020 for the years 2018, 2019 and 2020 from Bucharest, as in Fig. 5 . 


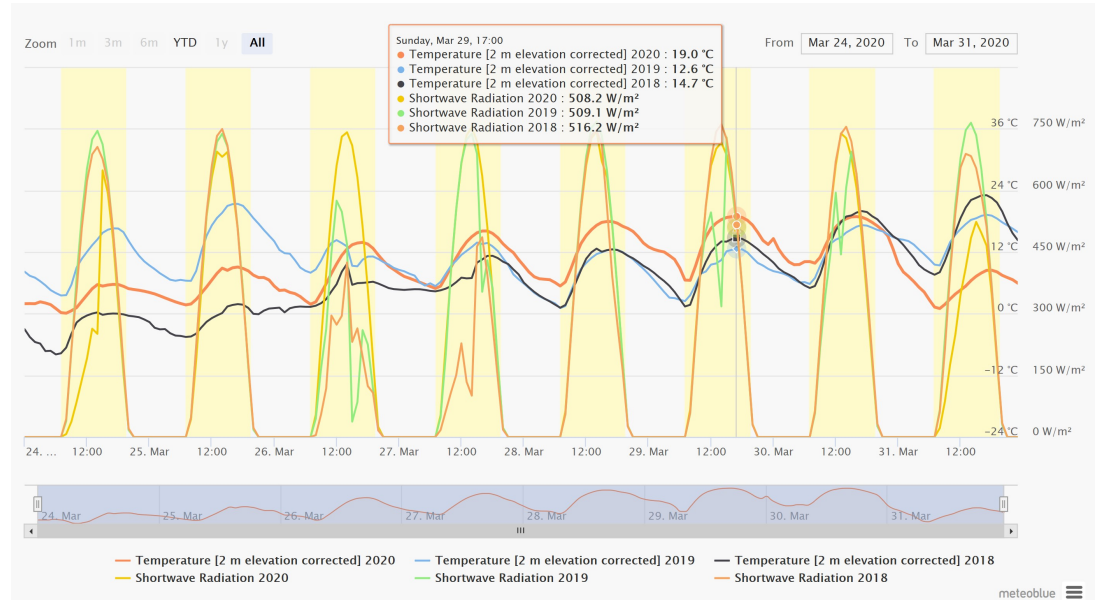

Fig. 5. Graphical representation values of temperature and solar radiation achieved between March 24-31 for the years 2018, 2019 and 2020 from Bucharest

In case of the graph presented in Fig. 5, it is observed that at 5:00 pm when the air temperature had the highest value, for the years 2018, 2019 and 2020 there were constant values of solar radiation, between March 24-31 for the years 2018, 2019 and 2020 from Bucharest, different values between $516.2 \mathrm{~W} / \mathrm{m}^{2}$ in $2018,509.1 \mathrm{~W} / \mathrm{m}^{2}$ in 2019 , respectively $508.2 \mathrm{~W} / \mathrm{m}^{2}$ in 2020 . For choosing the solar collector from the component of the heat supply in the vegetable solar during the cold weather of the year (October-December and February-April), the power of the solar radiation from which a square meter of solar collector for the location from Bucharest (Table 1).

Table 1. Average values of solar radiation power per square meter of solar collector in Bucharest

\begin{tabular}{|c|c|c|c|c|c|c|}
\hline Month & II & III & IV & X & XI & XII \\
\hline & \multicolumn{7}{|c|}{ The power of solar radiation $\mathrm{W} / \mathrm{m}^{2} / \mathrm{zi}$} \\
\hline Clear sky & 420 & 639 & 799 & 416 & 296 & 140 \\
\hline Covered sky & 215 & 318 & 405 & 243 & 162 & 68 \\
\hline
\end{tabular}

Analyzing the data in Table 1, it was found that the average power of solar radiation that can benefit a square meter of solar collector in cloudy weather is $235.2 \mathrm{~W} / \mathrm{m}^{2} / \mathrm{day}$, of which $221.1 \mathrm{~W} / \mathrm{m}^{2} /$ day can be captured by a solar collector of $1 \mathrm{~m}^{2}$ that has an absorption coefficient of at least $94 \%$. Following a technical analysis regarding the solar collectors sold in Romania, the solar collector with 30 heat-pipe drained Sontec SPA 30 58/1800 was chosen, which has the following main technical characteristics: the total area of $4.95 \mathrm{~m}^{2}$ material of the heat pipe: copper with $99.93 \%$ purity bonded with silver alloy, capacitor size: $\varnothing 14$ x 60, tube length: $1800 \mathrm{~mm}$, tube diameter: outside: $58 \mathrm{~mm}$ and inside: $47 \mathrm{~mm}$, glass thickness: $1.6 \mathrm{~mm}$, glass material: borosilicate, absorption coefficient: $\min .94 \%$, emission coefficient: max. $8 \%$ [16]. In these conditions, it was possible to design the heat production plant in greenhouse with has siz $9 \times 30$ m covered with polyethylene wrap with triple layer 200 microns, by supplementing with the following main components: two solar panels Sontec SPA 30 58/1800 with 30 vacuum heat pipes, a solar boiler with 2500 liter Sunsystem SON 500 coils, a Grundfos Solar Oventrop 25-65 130 thermally insulated pump assembly with thermometer, flow meter, manometer, 35 liter expansion vessel, a flexible stainless steel connection for the vessel expansion, a $180^{\circ} \mathrm{C}$ solar vent, a 1 "thermostatic mixing valve, connecting pipes and a SR288 solar automation system with three temperature sensors. 


\section{Conclusions}

- Theoretical studies carried out allowed to design a heat supply installation for the cold period of the year using solar collectors with vacuum tubes for heating the interior of a vegetable solar with hot water aerothermal;

- The average values of the solar radiation power per square meter of the solar collector, can easily be used in other indicative calculations for rapid predimensioning of the different types of solar collectors, being even more useful as, as a rule, such values are not indicated by manufacturing companies.

This work was supported by a grant of the Romanian Ministry of Education and Research, through Programme NUCLEU, ctr. nr. 5N / 07.02.2019, project PN 191002 01-Development innovative technologies within SMART farms and also Programme 1 - Development of the national researchdevelopment system, subprogramme 1.2 - Institutional performance - Projects for financing excellence in RDI, contract no. 16PFE.

\section{References}

1. E. Maican, I. C Dutu, G. Matache, C. Dumitrescu, I.Pavel, CFD analysis of an improved tlud based equipment for heating small greenhouses and hothouses, INMATEH - A. E., 53, 8, (2017)

2. E. Murad, C. Sima, T. Chereches, Gasification of corn stover, U.P.B. Sci. Bull., Series D, 72, 6, (2010)

3. D. Taban, A. Pop, C. Dobre, V. Apostol, T. Prisecaru, Establishing the optimal positioning of a three system vertical solar captors according to geographical orientation, Rev. Term., 1, 6, (2018)

4. Y. Tian, C.Y. Zhao, A review of solar collectors and thermal energy storage in solar thermal applications, App. Energ, 104, 55 (2013)

5. https://www.reeco.ro/energie-termica-solara/

6. B. Tanase, A. Gheorghian, M. Zamfir, V. Badescu, H. Pop, Comparative study on the positioning of solar collectors vertically or horizontally taking into account the restrictive conditions imposed by the dimensions of the renewable energy production system, Rev. Term., 2, 4, (2018)

7. http://energystreet.ro/fotovoltaice/harta-solara-a-romaniei/

8. F. Gáspár, V. Ros, Comparative study of solar collectors with flat and spherical surfaces through prism solar energy conversion efficiency in thermal energy, Rev. St. and Eng. 20, 8, (2011)

9. http://www.calorserv.ro/articole/panouri-solare/sistemul-solar-termic-panouri-solare

10. *** Ctr. nr. 5N / 07.02.2019, PN 191002 01, NUCLEU - SMART-BITECH, (2009)

11. https://www.seretransilvania.ro/ro/solarii-profesionale/solarii-gotice/solar-gotic9m/solar-gotic-9x30m-folie-dubla-inflata.html

12. I. Ziemelis, L. Kancevica, Z. Jesko and H. Putans, Calculation of energy produced by solar collectors, Eng. for Rul. Dev., (2009)

13. https://www.meteoblue.com/ro/vreme/historyclimate/climatemodelled/bucure $\% \mathrm{C} 8 \% 99$ ti_rom $\% \mathrm{C} 3 \% \mathrm{~A} 2$ nia 683506

14. http://www.meteoromania.ro/despre-noi/meteorologie-operationala/activitati-debaza/actinometrie/

15. https://www.meteoblue.com/ro/historyplus

16. https://www.sistemepanourisolare.ro/colector-solar-30-tuburi-vidate-heat-pipe-sontec$\underline{\text { spa-30 }}$ 